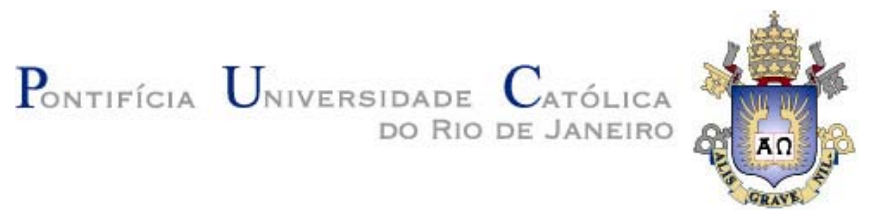

Marco Antonio Díaz Díaz

\title{
Análise do Ciclo de Vida do Etanol Brasileiro Visando à Certificação Ambiental
}

\begin{abstract}
Dissertação de Mestrado
Dissertação apresentada como requisito parcial para obtenção do título de Mestre pelo Programa de Pós-Graduação em Engenharia Mecânica da PUC-Rio.

Orientador: Marcos Sebastião de Paula Gomes
\end{abstract}

Rio de Janeiro

Abril de 2011 


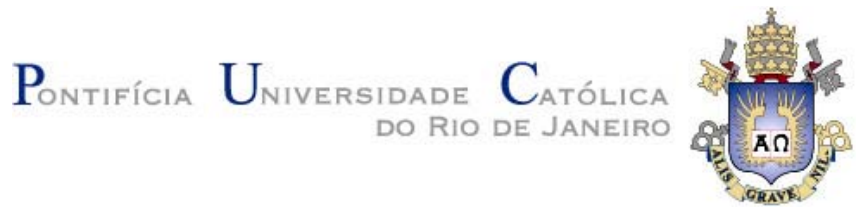

Marco Antonio Díaz Díaz

\section{Análise Do Ciclo De Vida do Etanol Brasileiro Visando à Certificação Ambiental}

Dissertação apresentada como requisito parcial para obtenção do título de Mestre pelo Programa de Pós-Graduação em Engenharia Mecânica do Centro Técnico Científico da PUC-Rio. Aprovada pela Comissão Examinadora abaixo assinada.

Prof. Carlos Valois Maciel Braga

Departamento de Engenharia Mecãnica - PUC-Rio

Prof. Carlos Alberto Aragão de Carvalho Filho Universidade Federal do Rio de Janeiro

Prof. José Eugenio Leal

Coordenador Setorial do

Centro Técnico Científico - PUC-Rio

Rio de Janeiro, 29 de Abril de 2011 
Todos os direitos reservados. É proibida a reprodução total ou parcial do trabalho sem autorização da universidade, do autor e do orientador.

\section{Marco Antonio Díaz Díaz}

Graduou-se em Engenharia Industrial na Universidade Nacional de San Agustin, Arequipa- Perú, em 2008. Atua na área de Engenharia Industrial e Engenharia Ambiental, tem trabalhado na elaboração e avaliação de projetos de inversão. Atua na Área de Petróleo e Energia com ênfase em Sistemas Energéticos e Avaliação Ambiental.

Ficha Catalográfica

Díaz Díaz, Marco Antonio

Análise do ciclo de vida do etanol brasileiro visando à certificação ambiental / Marco Antonio Díaz Díaz; orientador: Marcos Sebastião de Paula Gomes. $-2011$.

115 f. : il. (color.) ; $30 \mathrm{~cm}$

Dissertação (mestrado)-Pontifícia Universidade Católica do Rio de Janeiro, Departamento de Engenharia Mecânica, 2011.

Inclui bibliografia

1. Engenharia mecânica - Teses. 2. Avaliação do ciclo de vida (ACV). 3. Balanço energético. 4. Certificação Ambiental. 5. Etanol de cana-de-açúcar. I. Gomes, Marcos Sebastião de Paula. II. Pontifícia Universidade Católica do Rio de Janeiro. Departamento de Engenharia Mecânica. III. Título. 
Para meus pais, Rosa e Felipe. 


\section{Agradecimentos}

Ao meu orientador, Prof. Marcos Sebastião de Paula Gomes, pela dedicação e por ter confiado na minha capacidade.

Ao Robert Boddey, pela disponibilização dos dados.

Às agências CAPES e FAPERJ, pelos auxílios concedidos, sem os quais este trabalho não poderia ter sido realizado.

Aos colegas e amigos da Universidade, pela troca de conhecimento, experiências e pela presença nos grandes e pequenos momentos.

Aos funcionários do Departamento de Engenharia Mecânica da PUC-Rio, pelos serviços e presteza no atendimento de todas as minhas necessidades

Aos meus pais, pela educação, atenção e carinho de sempre.

Às minhas irmãs Angela e Rocio e a minha sobrinha Alejandra Luciana.

A todos vocês o meu mais profundo agradecimento. 


\section{Resumo}

Díaz, Marco Antonio Díaz; Gomes, Marcos Sebastião de Paula. Análise do ciclo de vida do etanol brasileiro visando à certificação ambiental. Rio de Janeiro, 2011. 115p. Dissertação de Mestrado - Departamento de Engenharia Mecânica, Pontifícia Universidade Católica do Rio de Janeiro.

Em dezembro de 2008, o Parlamento Europeu aprovou um acordo para reduzir em 20\% as emissões de GEE até 2020, sendo que os biocombustíveis irão responder por $10 \%$ dos combustíveis utilizados no setor de transportes. Assim, se o Brasil quiser se transformar em um fornecedor de etanol para aquela região, não basta produzir um combustível eficiente na redução das emissões de GEE. Para que seja aprovado para consumo no exterior, ele deverá passar por um processo de certificação. Esta dissertação tem como objetivo avaliar o consumo de energia, a produção de energia renovável e as emissões atmosféricas dos principais gases de efeito estufa $\left(\mathrm{CH}_{4}, \mathrm{~N}_{2} \mathrm{O}\right.$ e $\left.\mathrm{CO}_{2}\right)$ do etanol a partir da cana brasileira, levando em conta todas as entradas/saídas do ciclo de produção usando a metodologia da avaliação do ciclo de vida (ACV). O sistema analisado inclui o plantio de cana, o manejo da cultura, a colheita, as atividades na usina, e a distribuição do etanol. Leva-se em conta as condições impostas pelos aspectos ambientais, legais, regulatórios e de mercado que atuam como condicionantes para uma futura certificação do etanol brasileiro. Os resultados mostram que:

(i) O plantio da cana apresenta maior potencial para o consumo de recursos não renováveis devido ao uso intensivo de óleo diesel e de agrotóxicos.

(ii) A atividade de colheita gera a maior emissão de GEE devido à queima da palha da cana de açúcar.

(iii) Também se mostrou que a expansão do cultivo da cana-de-açúcar e da produção de etanol não afeta diretamente a produção de alimentos e o desflorestamento amazônico.

\section{Palavras-chave}

Avaliação do ciclo de vida (ACV); Balanço energético; Certificação Ambiental; Etanol de cana-de-açúcar. 


\section{Abstract}

Díaz, Marco Antonio Díaz; Gomes, Marcos Sebastião de Paula (Advisor). Life cycle assessment of the Brazilian sugarcane ethanol aiming its environmental certification. Rio de Janeiro, 2011. 115p. MSc. Dissertation - Departamento de Engenharia Mecânica, Pontifícia Universidade Católica do Rio de Janeiro.

In December 2008, the European Parliament approved an agreement for $20 \%$ reduction in GHG emissions by 2020 with the biofuels accounting for $10 \%$ of the fuels used in transport. Therefore, if Brazil wants to become an ethanol supplier for this region, it is not enough to produce an efficient fuel for reducing GHG emissions. In order to be approved for consumption abroad, it must go through a certification process. In this dissertation we develop a Life Cycle Assessment (LCA) for evaluating the energy consumption and the principal emissions of greenhouse gases $\left(\mathrm{CH}_{4}, \mathrm{~N}_{2} \mathrm{O}\right.$ and $\left.\mathrm{CO}_{2}\right)$ associated with the ethanol produced from Brazilian sugarcane, taking into account all the inputs/outputs into and from the production cycle. The system analyzed includes the sugarcane sowing, the plantation handling, the harvesting, the industrial activities, and the ethanol distribution. Taking into account the conditions imposed by environmental, legal, and market aspects, that may represent constraints for the future certification of the Brazilian ethanol. The results indicate that:

(i) The sugarcane sowing has the higher potential for the consumption of nonrenewable resources due to intensive use of pesticides and diesel.

(ii) The harvesting generates the highest GHG emissions due to sugarcane burning.

(iii) It was also concluded that the expansion of the sugarcane areas and the ethanol production did not directly affect food production and the Amazon deforestation.

\section{Keywords}

Life cycle assessment (LCA); Energy Balance; Environmental Certification; Sugarcane Ethanol. 


\section{Sumário}

1 Introdução

2 Revisão Bibliográfica 17

$\begin{array}{lll}2.1 & \text { Avaliação de ciclo de vida } & 17\end{array}$

2.1.1 Metodologia da Análise de Ciclo de Vida 18

2.2 Antecedentes da aplicação de ACV para energia e biocombustíveis 23

2.3 A certificação ambiental dos biocombustíveis 26

2.3.1 Primeiro Projeto de Sistemas de Certificação Socioambiental $\begin{array}{ll}\text { para cana-de-açúcar } & 26\end{array}$

2.3.2 Programa Brasileiro de Certificação de Biocombustíveis do $\begin{array}{ll}\text { INMETRO } & 29\end{array}$

2.3.3 Esforços fora do Brasil 30

2.3.3.1 Metodologias propostas 32

2.3.3.2 Estándares e princípios 33

2.3.3.3 Critérios e Indicadores 34

2.3.4 Uso do solo 34

2.3.5 Perda de solo devido à erosão 35

2.3.6 Zoneamento Agroecológico 36

3. Avaliação da cadeia do etanol da cana-de-açúcar 38

3.1 Estrutura Atual do Setor Sucroalcooleiro Brasileiro 38

3.2 Ciclo de vida do Etanol da cana-de-açúcar 40

3.3 Avaliação do ciclo de vida do Etanol da cana-de-açúcar 51

3.4 Inventário do Ciclo de Vida do Etanol da cana-de-açúcar 53

3.4.1 Energia fóssil empregada na produção de etanol 57

3.4.2 Quantificação das emissões de GEE 69

4. Resultados do Inventário do Ciclo de Vida 72

$\begin{array}{lll}4.1 & \text { Uso de Energia } & 74\end{array}$ 
4.1.1 Consumo de recursos renováveis (água).

4.1.2 Consumo de recurso fósseis. 75

4.1.3 Consumo de energia. 75

4.1.4 Rendimento energético líquido 76

$\begin{array}{lll}4.1 .5 & \text { Eficiência Energética } & 77\end{array}$

$\begin{array}{ll}4.2 \text { Uso do solo } & 79\end{array}$

4.3 Perda de solo devido à erosão 80

$\begin{array}{lll}4.4 & \text { Emissões atmosféricas } & 81\end{array}$

4.5 Desflorestamento amazônico VS Produção de etanol 83

4.6 Produção de alimentos VS produção de etanol 85

4.7 Zoneamento Agroecológico 86

4.8 Análise de Incertezas 88

5. Conclusões 90

$\begin{array}{lll}5.1 \text { Conclusões } & 90\end{array}$

5.2 Recomendações para trabalhos futuros 92

6. Referências Bibliográficas 93

Apêndice 1 Consumo de Óleo Diesel nas operações de campo para a produção de cana-de-açúcar. 101

Apêndice 2 Consumo de energia nos trabalhos manuais no cultivo da cana-de-açúcar

Apêndice 3 Consumo de energia no transporte da cana do campo até a usina

Apêndice 4 Consumo de Água 
Anexo 1: Cálculo da energia fóssil consumida na fabricação e manutenção do maquinário agrícola.

Anexo 2 Equipamentos e implementos utilizados nas etapas de

plantio, manejo da cultura e colheita. Fonte: Macedo et al. (2004)

Anexo 3 Metodologia de cálculo do uso de energia fóssil na usina.

Anexo 4 Valores de incertezas para fatores energéticos, segundo as considerações de expertos IPCC. 


\section{Lista de figuras}

Figura 1. Fases da Avaliação do Ciclo de Vida.

Figura 2. Representação esquemática dos processos envolvidos na cadeia produtiva do Etanol.

Figura 3. "Mobilizadores" locais e globais para biocombustíveis e bioenergia.

Figura 4. Fronteiras da cadeia dos biocombustíveis. 33

Figura 5. Operação de preparo do solo. 42

Figura 6. Plantio manual. $\quad 43$

Figura 7. Aplicação de herbicida com tratores. 44

Figura 8. Queima da palha da cana-de-açúcar. 46

Figura 9. Lavagem da cana-de-açúcar. $\quad 47$

Figura 10. Caldeira de combustão do bagaço 48

Figura 11. Co-geração de energia elétrica. 49

Figura 12. Fertirrigação de vinhaça por aspersão. 50

Fonte: Rossetto e Santiago (2007). 50

Figura 13. Ciclo de vida do etanol de cana-de-açúcar. 51

Figura 14. Sistema de produto do etanol. 53

Figura 15 Fluxograma de energia e emissões de GEE do ciclo de vida do etanol.

Figura 16. Bioma Amazônia, Bioma Pantanal e Bacia do Alto Paraguai no Território Brasileiro.

Figura 17. Mapa da Usinas de Etanol no Brasil. 


\section{Lista de tabelas}

Tabela 1. Características dos principais sistemas de certificação aplicados na agropecuária. 28

Tabela 2. Princípios Ambientais e sociais adotados RTFO. 33

Tabela 3. Número de usinas e produção de Açúcar e Etanol na safra 2008-2009. 40

Tabela 4. Utilização de equipamentos agrícolas. 57

Tabela 5: Dados para o cálculo da média de consumo anual de combustível. 58

Tabela 6. Equipamentos e implementos no plantio da cana. 59

Tabela 7: Consumo de energia fóssil na etapa de plantio da cana. $\quad 60$

Tabela 8. Equipamentos e implementos no manejo da cultura. 62

Tabela 9. Consumo de energia fóssil na etapa de manejo da cultura.

Tabela 10. Participação da colheita mecânica e manual no total da área colhida na safra 2008-09. 64

Tabela 11. Equipamentos e Implementos empregados na colheita. 65

Tabela 12. Consumo de energia fóssil na etapa da colheita. 65

Tabela 13. Consumo de energia fóssil na etapa de produção de etanol na usina. $\quad 68$

Tabela 14. Consumo de energia fóssil na distribuição do etanol. $\quad 69$

Tabela 15. Consumo de água.

Tabela 16. Consumo de recursos não renováveis. 75

Tabela 17 . Consumo de energia não renovável. 76

Tabela 18. Rendimento energético líquido do sistema. 77

Tabela 19. Eficiência energética, razão energia fornecida/energia consumida. $\quad 79$

Tabela 20. Uso do solo. $\quad 80$

Tabela 21. Porcentagem das maiores emissões atmosféricas do ciclo de vida do etanol. 
Tabela 22. Quantidade de substâncias atmosféricas emitidas por hectare de cultivo de cana-de-açúcar num ano.

Tabela 23. Participação das lavouras substituídas pela cana de açúcar na safra 2008/2009.

Tabela 24. Comparação entre as áreas de cultivo substituídas pela cana de açúcar e as áreas estimadas por cultivo substituído. Tabela 25. Incertezas para cada uma das etapas do ciclo de vida do etanol de cana-de-açúcar. 


\section{Lista de quadros}

Quadro 1. Produção de Etanol e de Açúcar nos últimos 20 anos. $\quad 39$

Quadro 2. Cálculo e apresentação da planilha.. 56

Quadro 3. Uso de energia fóssil na produção de etanol segundo a atividade do ciclo de vida do etanol. 76

Quadro 4. Maiores emissões atmosféricas do ciclo de vida do etanol. 81

Quadro 5. Emissões de GEE na produção de etanol segundo as etapas do ciclo de vida do etanol.

82

Quadro 6. Comparação de Desflorestamento VS a produção da cana de açúcar processada.

84

Quadro 7. Comparação de Desflorestamento VS a produção de etanol. 84 